\title{
Colorectal endoscopic submucosal dissection at a low-volume centre: tips and tricks, and learning curve in a district hospital in Hong Kong
}

\author{
Deon HM Chong, CM Poon, HT Leong *
}

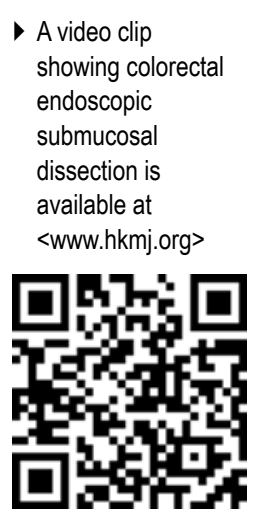

This article was published on 6 May 2016 at www.hkmj.org.

\section{A B S T R A C T}

Introduction: Colorectal endoscopic submucosal dissection is not a widely adopted procedure due to its technical difficulties. This study aimed to share the experience in setting up this novel procedure and to report the learning curve for such a procedure at a low-volume district hospital in Hong Kong.

Methods: This case series comprised 71 colorectal endoscopic submucosal dissections that were performed by a single endoscopist without experience in gastric or colorectal endoscopic submucosal dissection. Lesion characteristics, procedure time per unit area of tumour, en-bloc resection rate, $\mathrm{R} 0$ resection rate, complications, and length of stay were recorded prospectively. Results were compared for two consecutive periods to study the learning curve.

Results: Overall, 41 (57.7\%) tumours were located in the right colon, 21 (29.6\%) in the left colon, and nine $(12.7 \%)$ in the rectum. The median tumour area was $4 \mathrm{~cm}^{2}$ (range, $0.25-16 \mathrm{~cm}^{2}$ ). The median operating time was 105 (range, 47-342) minutes. The median procedure time per unit area of tumour was 24.9 $\mathrm{min} / \mathrm{cm}^{2}$. There was one instance of intra-operative bleeding that required conversion to laparoscopic colectomy. There was no postoperative haemorrhage.
The overall perforation rate was $15.5 \%$, in which one required conversion to laparoscopic colectomy. The overall morbidity rate was $16.9 \%$ and there was no mortality. The median hospital stay was 1 day (range, 0-11 days). The overall en-bloc resection rate and $\mathrm{R} 0$ resection rate was $81.2 \%$ and $58.0 \%$, respectively. Comparison of the two study periods revealed that procedure time per unit area of tumour decreased significantly from $31.5 \mathrm{~min} / \mathrm{cm}^{2}$ to $21.5 \mathrm{~min} / \mathrm{cm}^{2}$ $(\mathrm{P}=0.032)$. The en-bloc resection rate improved from $78.8 \%$ to $83.3 \%(\mathrm{P}=0.15)$. The $\mathrm{R} 0$ resection rate improved significantly from $39.4 \%$ to $75.0 \%(\mathrm{P}<0.01)$.

Conclusion: Untutored colorectal endoscopic submucosal dissection is feasible with acceptable clinical outcomes at a low-volume district hospital in Hong Kong.

\section{Hong Kong Med J 2016;22:256-62} DOI: 10.12809/hkmj154736

\section{DHM Chong, FRCSEd}

CM POon, FRCSEd

HT Leong *, FRCSEd

Department of Surgery, North District Hospital, Sheung Shui, Hong Kong

* Corresponding author: lamyn@ha.org.hk

New knowledge added by this study

Untutored colorectal endoscopic submucosal dissection (ESD) has an acceptable clinical outcome after 35 procedures at a low-volume centre.

Implications for clinical practice or policy

ESD can be safely performed at a low-volume centre

ESD can be started at the colorectum instead of the stomach.

\section{Introduction}

For many years, conventional endoscopic mucosal resection (EMR) and surgery were the only options for treating a large $(>20 \mathrm{~mm})$ sessile or flat colorectal lesion. Conventional EMR, however, often results in piecemeal removal and there is a significant local recurrence rate ranging from $7.4 \%$ to $17 \% .^{1-3}$ Full histological evaluation is also difficult.

Endoscopic submucosal dissection (ESD), pioneered in Japan for treating early upper gastrointestinal malignancy, was introduced in the late 1990 s by Yamamoto et $\mathrm{al}^{4}$ and Fujishiro et $\mathrm{al}^{5}$ to treat colorectal lesions. The technique has an advantage over EMR in that its effectiveness is not limited by size or shape of the lesion. In the past decade, colorectal ESD has been shown to be superior to EMR, in terms of higher en-bloc resection rate and lower recurrence rate. ${ }^{6}$ Colorectal ESD can be applied not only to adenoma, but also to intramucosal carcinoma and low-risk submucosal carcinoma, as defined by the Paris classification ${ }^{7}$ and the Japanese Society for Cancer of the Colon and Rectum. ${ }^{8}$ Recently, a largescale multicentre study has shown that ESD alone is adequate in the management of patients with lowrisk submucosal carcinoma and achieves an excellent 5 -year recurrence-free survival of $98 \%$ and 5-year 
overall survival of $94 \%{ }^{9}$

Despite the growing evidence to support the use of colorectal ESD, it is not established as a standard treatment outside Japan. The drawbacks of colorectal ESD include longer operating time ${ }^{6}$ and higher complication rates, especially perforation. Although the perforation rate of ESD is much higher than that of EMR, most ESD perforations can be treated conservatively by clip closure during endoscopy. ${ }^{10,11}$ In a multicentre study of iatrogenic perforations in Japan, the respective EMR and ESD perforation rate was $0.58 \%$ and $14 \%$ in 15160 therapeutic colonoscopies. ${ }^{12}$ Endoscopic clipping failed in $43.5 \%$ of ESD perforations and surgical intervention was necessary. ${ }^{12}$

Perhaps one of the major hurdles to its general application is that it is a technically demanding procedure that is difficult to set up at a lowvolume district hospital. We would like to share our experience of applying this novel technique in a district hospital in Hong Kong.

\section{Methods}

\section{Case selection}

North District Hospital was a district hospital serving 700000 population with a case volume of 15 to 20 cases of ESD per year. Since the introduction of the ESD technique at the hospital in 2009, all lateral spreading tumours larger than $2 \mathrm{~cm}$ or those unable to be resected en bloc by conventional polypectomy were referred to a single endoscopist to determine the appropriateness of ESD. Colonoscopy was repeated by a single endoscopist to determine the location, size, and nature of each tumour by whitelight and narrow band imaging (NBI). Benign polyps not amendable to removal by EMR were triaged to ESD. Target biopsy was performed on Sano III lesions that were triaged to conventional laparoscopic colectomy. No tumours were excluded based on location.

\section{Preoperative evaluation of the depth of invasion}

Evaluation of the depth of invasion is important to determine the treatment strategy. To predict the depth of invasion, we used NBI colonoscopy, based on Sano's capillary pattern classification. The underlying principle is that angiogenesis is critical for transition of a premalignant lesion to a malignant one and the microcapillary pattern changes in this process. Sano et $\mathrm{al}^{13}$ focused on this microcapillary difference based on their histopathological findings and devised three classifications: types I, II, and III. Type III was further subdivided into IIIA and IIIB. ${ }^{14}$

The diagnostic accuracy of NBI colonoscopy in differentiating a neoplastic from non-neoplastic lesion is superior to conventional colonoscopy

\section{一間低手術量的中心內進行大腸內鏡秥膜下剝離} 術：香港一所分區醫院的技巧、竅門和學習曲線

\author{
莊凱雯、潘志明、梁慶達
}

引言：大腸內鏡黏膜下剝離術的技術層面要求較高，因此不是一個廣 泛採用的程序。本研究旨在分享香港分區醫院一間低手術量的中心內 開始進行此項新技術的經驗, 並報告其學習曲線。

方法：在本病例系列內, 所有 71 例大腸內鏡黏膜下剝離術均由一名內 鏡專科醫生進行, 這名醫生以往對胃和大腸內鏡秥膜下剝離術並無經 驗。本研究前瞻記錄了病人腫瘤特性、每個腫瘤單位面積所需的手術 時間、整塊切除率、R0切除率、併發症和住院時間。比較前後兩個階 段的手術結果以研究此項技術的學習曲線。

結果：腫瘤位置方面，41例（57.7\%）位於右結腸，21例（29.6\%） 位於左結腸, 9 例 $\left(12.7 \%\right.$ ) 位於直腸。腫瘤面積中位數為 $4 \mathrm{~cm}^{2}$ (介 乎0.25-16 $\mathrm{cm}^{2}$ )。手術時間中位數為 105 分鐘（介乎47-342分鐘）。 每個腫瘤所需的手術時間為每平方厘米 24.9 分鐘。1 例因術內出血 須轉為腹腔鏡結腸切除術。沒有術後出血的病例。整體穿孔率為 $15.5 \%$, 其中 1 例需轉換為腹腔鏡結腸切除術。總患病率為 $16.9 \%$, 沒 有死亡病例。平均住院期 1 天（介乎 $0-11$ 天）。整塊切除率和 $\mathrm{R} 0$ 切除 率分別為 $81.2 \%$ 和 $58.0 \%$ 。比較前後兩個階段發現每個腫瘤所需的手術 時間由每平方厘米 31.5 分鐘顯著減至 21.5 分鐘 $(\mathrm{P}=0.032)$ 。整塊切 除率從 $78.8 \%$ 上升至 $83.3 \% （ \mathrm{P}=0.15 ）$. R0切除率從 $39.4 \%$ 顯著提高 至75.0\% $(\mathrm{P}<0.01)$

結論：香港分區醫院一間低手術量的中心內, 在未受訓練的情況下進 行大腸內鏡黏膜下剝離術, 且有可接受的臨床結果是可行的。

and equivalent to chromoendoscopy using indigocarmine..$^{15}$ For estimation of the depth of invasion, the sensitivity, specificity, and diagnostic accuracy of capillary pattern type III for differentiating pM-ca (intramucosal) or pSM1 (superficial) from pSM2-3 (deep) was $84.8 \%, 88.7 \%$ and $87.7 \%$, respectively. ${ }^{14}$ We preferred NBI colonoscopy because it is fast and easy to use, without the need to spray dye as in chromoendoscopy.

\section{Preparation}

The procedure was performed in the operating theatre with the patient under conscious sedation. All patients were assessed by an anaesthetist in a preoperation clinic.

Patients were instructed to eat a low-residue diet 2 days before the procedure and a fluid diet on the day before ESD. Bowel preparation with 4. L polyethylene glycol solution was given on the day before ESD. Prophylactic antibiotics were not prescribed.

\section{Setting}

All procedures were performed in the operating theatre. This ensured that all equipment was on hand should conversion to an open procedure be required, for example, if there was full-thickness perforation that could not be closed endoscopically. 


\section{Endoscopic system}

In our hospital, ESD was performed using a singlechannel colonoscope (CF-H180AL; Olympus, Tokyo, Japan). This colonoscope was a high-density television compatible with a wide angle of $170^{\circ}$, $3.7-\mathrm{mm}$ instrument channel, and auxiliary water jet. A short transparent hood was fitted to the tip of the endoscope so that the whole ring could be seen in endoscopic view. Carbon dioxide was used for insufflation to decrease patient discomfort. We used a high-frequency electrosurgical generator (ESG100; Olympus, Tokyo, Japan) with a peristaltic pump (AFU-100; Olympus, Tokyo, Japan). The energy setting used for incision and dissection was "forced coagulation 2" 30W, whereas "soft coagulation" $100 \mathrm{~W}$ was used for haemostasis.

\section{Cutting devices}

In our initial practice, we used the Flex Knife (KD630L; Olympus, Tokyo, Japan) to perform the procedure. It had a loop-shaped tip that allowed easy control in any direction, as it was soft and flexible. Nonetheless, we found it difficult to adjust the length of the tip and there was frequent accumulation of debris around the tip. We then changed to Dual Knife (KD-650L; Olympus, Tokyo, Japan) with a fixed length $(1.5 \mathrm{~mm})$ and hence a more stable knife movement. More recently, we have used Flush Knife BT (DK2618JB/DK2618JN; Fujifilm, Saitama, Japan) for dissection. It has a ball tip of fixed length that touches a wider part of tissue and enhances haemostasis. The knife has a water jet channel and achieves two purposes: (1) it can wash away any tissue that accumulates around the tip, thereby maintaining the sharpness of the knife; and (2) submucosal normal saline injection can be performed without the need to change the instrument for further hyaluronate injection.

\section{Injecting agent}

We used a mixture of $10 \%$ sodium hyaluronate (LG Chemical, South Korea) and 1:200000 adrenaline saline at a ratio of 1:1.5. This solution was chosen for three reasons: the addition of adrenaline can produce a haemostasis effect; dilution of sodium hyaluronate made it less viscous and thus easier to inject; and it reduced the amount used of the relatively more expensive sodium hyaluronate.

\section{Endoscopist}

All ESD procedures were performed by a single experienced endoscopist who had performed more than 500 therapeutic colonoscopic procedures and more than 200 laparoscopic colectomies. The ESD procedure was implemented by the endoscopist following completion of training on an animal model in the Second Master Workshop on Novel
Endoscopic Technology \& Endoscopic Submucosal Dissection in 2009 at Prince of Wales Hospital in Hong Kong, which was organised by the Department of Surgery, The Chinese University of Hong Kong (http://www.surgery.cuhk.edu.hk/events/2009-0722-ESD.pdf). The workshop included both lecture sessions and hands-on sessions to perform ESD in a pig. The endoscopist had no experience in gastric or colorectal ESD. He received further overseas training in ESD in 2011 at Osaka Medical Center for Cancer and Cardiovascular Diseases in Japan as a clinical observer with hands-on animal model training.

\section{Procedure}

With the patient initially lying in the left lateral position, a full colonoscopy was first performed to confirm and locate the site of pathology. Patients were then re-positioned such that the lesion was at an anti-gravitational position in the endoscopic view at 6 o'clock. This could be easily achieved by seeing the injected water pooling opposite to the lesion. In this position, the gravitational force aided in retracting the lesion away from the submucosal plane during dissection. We then injected 1:100 000 adrenaline saline at $1 \mathrm{~cm}$ distal to the lesion, aiming at the submucosal layer. This could be ascertained by seeing the formation of a dwell. With the injecting needle still in situ, the solution was then changed to the mixture of adrenaline saline and sodium hyaluronate to provide a precipitous elevation of sufficient height. After elevating the lesion, a mucosal incision was made proximal to the lesion. The mucosal incision was started at the proximal two thirds of the lesion. After mucosal incision, the submucosal plane was dissected with the submucosa dissected away from the muscle layer. Care was taken to manipulate the dissection plan parallel to the intestinal wall to prevent perforation. When a more than 1-mm diameter vessel was detected, it was coagulated using haemostasis forceps (Radial Jaw 4; Boston Scientific, US). When the flap was sufficient for retraction, the mucosal incision was completed. In case of perforation, the defect was closed with endoscopic clipping (EZ Clip; Olympus, Tokyo, Japan). The resected area was not closed as healing usually occurred in a few weeks without complications. ${ }^{16}$

\section{Histological assessment}

All specimens were pinned on a piece of foam and fixed in formalin. Histological type, depth of invasion, as well as lateral and vertical resection margins were recorded. En-bloc resection was defined as one-piece resection of an entire lesion as observed endoscopically. R0 resection was defined as clear lateral and vertical resection margin.

\section{Post-endoscopic submucosal dissection}

All patients were allowed to resume a full diet on the 
same day. We performed no routine blood tests or imaging and patients were discharged the next day if there were no signs of perforation or haemorrhage. Postoperative haemorrhage was defined as clinical evidence of bleeding manifested by melena or haematochezia that required endoscopic haemostasis within 0 to 14 days of the procedure. ${ }^{11}$

\section{Follow-up}

All patients were followed up in clinic 2 weeks later to review the pathology report. Additional surgery would be offered in case of carcinoma with one of the following criteria: (1) margin involved; (2) $>1 \mathrm{~mm}$ submucosal invasion; (3) positive lymphovascular permeation; (4) poorly differentiated adenocarcinoma, signet ring cell carcinoma, or mucinous carcinoma; or (5) high-grade tumour budding. ${ }^{17}$ Surveillance colonoscopy was performed 1 year after ESD.

\section{Statistical analysis}

All continuous variables were described as median and range. To study the learning curve, all patients were grouped chronologically into two periods: group 1 with cases 1 to 35; and group 2 with cases 36 to 71. Comparisons between non-parametric data were done with Mann-Whitney $U$ test, while Chi squared test was used for categorical variables. A P value of $<0.05$ was considered statistically significant.

\section{Results}

From March 2009 to December 2013, a total of 71 ESDs were performed. Characteristics of the patients are shown in Table 1.

There was one conversion to laparoscopic colectomy due to intra-operative bleeding that could not be controlled endoscopically (40 mm x $15 \mathrm{~mm}$ tumour at the transverse colon). For perforation, there were 11 (15.5\%) perforations: eight in the colon and three in the rectum, all were noticed during the ESD. Endoscopic clipping was successful in 10 of the perforations. The median number of clips used was 2 (range, 1-6). One perforation required conversion to laparoscopic colectomy (30 $\mathrm{mm}$ x $5 \mathrm{~mm}$ tumour at the sigmoid colon). Both laparoscopic operations were uneventful and patients were discharged without any surgical complications. The overall morbidity rate was $16.9 \%$ including bleeding and perforation and there was no mortality. The median postoperative stay was 1 day (range, 0-11 days).

Of the 69 patients who completed the endoscopic procedure, en-bloc resection was successful in $56(81.2 \%)$ patients, of whom 19 (27.5\%) required additional snare (SD-210U-25, Snare Master; Olympus, Tokyo, Japan) to complete the en-bloc resection. Conversion to piecemeal resection by snare occurred in 14 (20.3\%) patients.
TABLE I. Characteristics of patients undergoing endoscopic submucosal dissection

\begin{tabular}{|c|c|}
\hline Characteristic & Data \\
\hline Age (years) ${ }^{\star}$ & $67(46-88)$ \\
\hline \multicolumn{2}{|l|}{ Sex } \\
\hline Male & $42(59.2 \%)$ \\
\hline Female & $29(40.8 \%)$ \\
\hline \multicolumn{2}{|l|}{ Location of tumour } \\
\hline Right colon & $41(57.7 \%)$ \\
\hline Left colon & $21(29.6 \%)$ \\
\hline Rectum & $9(12.7 \%)$ \\
\hline Tumour area $\left(\mathrm{cm}^{2}\right)^{\star}$ & $4(0.25-16)$ \\
\hline Procedure time (mins) ${ }^{\star}$ & $105(47-342)$ \\
\hline Procedure time per unit area $\left(\mathrm{min} / \mathrm{cm}^{2}\right)^{\star}$ & 24.9 \\
\hline Postoperative length of stay (days) ${ }^{\star}$ & $1(0-11)$ \\
\hline Perforation rate & $15.5 \%$ \\
\hline En-bloc resection rate & $81.2 \%$ \\
\hline Additional snare & $27.5 \%$ \\
\hline $\mathrm{R} 0$ resection rate & $58.0 \%$ \\
\hline
\end{tabular}

Median (range) is shown

In these 69 patients, the resection margin was unclear in 15 patients as it was too close to the cauterised edge. These, together with piecemeal resection, were classified as R1 (29 patients in total). $\mathrm{R} 0$ resection was achieved in $40(58.0 \%)$ patients. The histopathological diagnosis was tubular adenoma for $26(36.6 \%)$ tumours, tubulovillous adenoma for $28(39.4 \%)$, villous adenoma for two (2.8\%), serrated adenoma for six (8.5\%), carcinoid for one (1.4\%) with involved margin, intramucosal carcinoma for two (2.8\%), and carcinoma with submucosal invasion for six (8.5\%). The ESD procedure was considered curative for the two patients with intramucosal carcinoma. One patient who had submucosal carcinoma refused further treatment because of a subsequent diagnosis of primary lung cancer. All other patients with submucosal carcinoma had curative interval laparoscopic surgeries. There was no residual tumour and no lymph node involvement found in the surgical specimen for any of these patients. The patient with rectal carcinoid also underwent subsequent interval laparoscopic total mesorectal excision: the pathology was well-differentiated carcinoid with invasion to the muscularis propria. There was one lymph node metastasis out of 11 lymph nodes retrieved.

\section{Recurrence and surveillance colonoscopy}

After excluding the six interval surgeries and two conversions to laparoscopic colectomy, the remaining 63 patients were offered colonoscopy surveillance of whom four refused and one defaulted from follow-up. Until August 2014, 51 patients had undergone surveillance colonoscopy and seven 
were awaiting colonoscopy. Recurrence of polyp occurred in seven $(13.7 \%)$ out of 51 patients: three recurrences occurred after piecemeal resection, another three recurrences occurred after additional snare to complete the en-bloc resection. All three cases had uncertain margin due to proximity to the cauterised edge. In one patient, recurrence occurred after successful en-bloc resection by ESD, in which the deep margin was clear but the circumferential margin was not certain.

\section{Learning curve between the two chronological groups}

All patients were grouped chronologically into two periods: group 1 with cases 1 to 35 ; and group 2 with cases 36 to 71 . The comparison between the two groups is shown in Table 2 . The median procedure time per unit area of tumour improved significantly from $31.5 \mathrm{~min} / \mathrm{cm}^{2}$ to $21.5 \mathrm{~min} / \mathrm{cm}^{2}(\mathrm{P}=0.032)$.

There were three $(8.6 \%)$ perforations in group 1 ; one of them required conversion to laparoscopic colectomy. There were eight $(22.2 \%)$ perforations in group 2; all managed successfully by endoscopic clipping. There was no significant difference in perforation rate $(\mathrm{P}=0.054)$. The intra-operative bleeding that required a conversion to laparoscopic colectomy also belonged to group 1 .

For the 33 patients in group 1 who completed the endoscopic procedure, en-bloc resection was successful in 26 (78.8\%), while $30(83.3 \%)$ out of 36 patients in group 2 had successful en-bloc resection. This trend of improvement, however, did not reach statistical significance $(\mathrm{P}=0.15)$. Among these successful en-bloc resections, 15 (57.7\%) out of 26 patients in group 1 and four (13.3\%) out of 30 patients in group 2 required additional snare to complete the en-bloc resection $(\mathrm{P}<0.01)$.

$\mathrm{R} 0$ resection rate had improved significantly in group 2 despite a lower rate of snare application: 13
(39.4\%) of 33 patients in group 1 had R0 resection, whereas in group 2, 27 (75.0\%) of 36 patients had R0 resection $(\mathrm{P}<0.01)$.

The median postoperative stay was 1 day in both groups and was not significantly different $(\mathrm{P}=0.25)$. The median postoperative stay in patients with perforation in group 1 and group 2 was 1 day (range, 1-7 days) and 2 days (range, 1-11 days), respectively $(\mathrm{P}=0.73)$.

\section{Discussion}

Colorectal ESD has been shown to be feasible and safe when performed at expert centres in Japan. In a recent prospective multicentre cohort study involving 1111 patients in Japan, the reported en-bloc resection rate was $88 \%$ and $\mathrm{R} 0$ resection rate was $89 \%{ }^{11}$ The total perforation rate was only $5.3 \%$ and postoperative bleeding was $1.5 \% .{ }^{11}$ Nonetheless, these excellent results are largely reported from Japan. Colorectal ESD is technically difficult, as the lumen is narrow and angulated and the very thin wall presents a high risk of perforation. In Japan, endoscopists are first required to gain experience in gastric ESD, which is technically less demanding, before they move on to colorectal ESD. ${ }^{18}$ This is not possible in western and Asian countries outside Japan, where early gastric cancer is much less prevalent. In a recent review of 82 rectosigmoid ESD from a tertiary centre in Germany, the en-bloc resection rate and $\mathrm{R} 0$ resection rate was only $81.6 \%$ and $69.7 \%$, respectively. ${ }^{19}$ This reflects the difficulty in generalising this novel procedure in other counties outside Japan, and an even greater challenge to lowvolume district centres that lack local expertise.

The low case volume and the absence of expertise in western countries leads to the development of untutored colorectal ESD when it is impossible to have a step-up approach in ESD training starting from the stomach before proceeding to colon. The

TABLE 2. Comparison between the two chronological groups

\begin{tabular}{|c|c|c|c|}
\hline & Group 1 (case No. 1-35) & Group 2 (case No. 36-71) & $P$ value \\
\hline Location & & & - \\
\hline Right colon & $22(62.9 \%)$ & $19(52.8 \%)$ & \\
\hline Left colon & $10(28.6 \%)$ & $11(30.6 \%)$ & \\
\hline Rectum & $3(8.6 \%)$ & $6(16.7 \%)$ & \\
\hline Tumour area $\left(\mathrm{cm}^{2}\right)^{*}$ & $4(0.25-16)$ & $4(1.5-9)$ & 0.23 \\
\hline Procedure time (mins) ${ }^{\star}$ & $125(53-323)$ & $98(47-342)$ & 0.19 \\
\hline Procedure time per unit area $\left(\mathrm{min} / \mathrm{cm}^{2}\right)^{\star}$ & 31.5 & 21.5 & 0.032 \\
\hline Perforation rate & $8.6 \%$ & $22.2 \%$ & 0.054 \\
\hline En-bloc resection rate & $78.8 \%$ & $83.3 \%$ & 0.15 \\
\hline Additional snare & $45.5 \%$ & $11.1 \%$ & $<0.01$ \\
\hline $\mathrm{R} 0$ resection rate & $39.4 \%$ & $75.0 \%$ & $<0.01$ \\
\hline Postoperative stay (days)* & $1(1-7)$ & $1(1-11)$ & 0.25 \\
\hline
\end{tabular}


reported learning curve for untutored colorectal ESD has an acceptable outcome, however. Berr et $\mathrm{al}^{20}$ reported a case series of 48 colorectal ESDs with $76 \%$ en-bloc resection, $14 \%$ perforation, and $4 \%$ requirement for surgical intervention. This compared favourably with results in Japan. ${ }^{11}$ Another learning curve study of colorectal ESD found procedure time could be significantly shorter after 25 procedures. ${ }^{21}$

With a similar situation in Hong Kong, this study showed that untutored colorectal ESD is safe and feasible. Results demonstrated obvious improvement after 35 procedures, as evidenced by the significant reduction in combined ESD and EMR with snare from $45.5 \%$ to $11.1 \%$. Procedure time per unit area of tumour as well as R0 resection rate also significantly improved after 35 cases. Although there were more perforations in group 2 , it did not determine adverse outcome. None of the perforations in group 2 required conversion to laparoscopic colectomy. There was no significant impact on hospital stay. The higher perforation rate in group 2 may reflect a second learning curve to perform a complete ESD procedure without the assistance of a hybrid technique to achieve a reasonable $\mathrm{R} 0$ resection rate. A perforation rate comparable with the Japanese series ${ }^{11}$ is expected in the third tranche of 35 patients.

Contrary to perforations in traditional therapeutic colonoscopies, all perforations in ESD were only 1 to $2 \mathrm{~mm}$ in size and were noticed intra-operatively, thus immediate endoscopic repair was possible. No patient required surgical intervention solely for treatment of perforation. The only conversion to laparoscopic colectomy in the initial learning curve aimed to offer one-stop treatment rather than treating perforations. In a multicentre review of colonoscopic perforations by Teoh et $\mathrm{al}^{22} 43(0.113 \%)$ perforations were found in 37971 colonoscopies. Only seven (43.8\%) out of 16 therapeutic colonoscopic perforations were noticed during the endoscopic procedure. The mean size of perforation was $0.98 \mathrm{~cm}$. The overall 30 -day morbidity and mortality rate was $48.7 \%$ and $25.6 \%$, respectively and the stoma rate was $38.5 \%$. This showed clearly that surgical outcome was much worse in conventional colonoscopic perforations compared with perforations in ESD, despite a much higher perforation rate of $15.7 \%$ in ESD group. ${ }^{22}$

After implementation of the ESD service, the

following were noted:

(1) Venue of procedure-operating theatre was chosen instead of an endoscopic unit to enable conversion to conventional laparoscopic colectomy without the need to change location as well as the ready availability of an anaesthetist to give conscious sedation.

(2) Mode of anaesthesia-in the first few patients, we performed ESD under general anaesthesia for patient comfort and in the event conversion to laparoscopic colectomy was necessary. Positioning of patients was clumsy particularly when a prone position was needed to perform the procedure. Subsequently conscious sedation by an anaesthetist was used instead. Patients could follow instructions for positioning and deeper sedation could be achieved if necessary. There were no complaints from patients about any discomfort during the procedure.

(3) Choice of injecting agents-albumin 20\% (Albumex 20; CSL, Australia) was used as submucosal injecting agent in the first few patients when sodium hyaluronate was not available. Albumin $20 \%$ has both a good cushioning effect without any inflammatory effect and the cost was much cheaper at $\mathrm{HK} \$ 2.7 / \mathrm{mL}$ compared with commercially available sodium hyaluronate at $\mathrm{HK} \$ 68 / \mathrm{mL} .{ }^{23}$ Yet sodium hyaluronate has the longest lasting cushioning effect among all injecting agents. We recommend its use whenever available.

(4) A mixture of adrenaline saline and sodium hyaluronate was favourable for the assistant to inject and a lesser volume of sodium hyaluronate was required. Moreover, there were no instances of postoperative haemorrhage, although it was difficult to conclude whether this was due to the addition of adrenaline saline.

(5) Endoscopic technique-in our initial practice, we performed a full circumferential mucosal incision before submucosal dissection. We noticed it was technically more difficult compared with a two-third circumferential incision, because firstly, the submucosal elevation was lost quickly due to faster leakage of injecting agent, and secondly, it was difficult to retract the lesion at the end of dissection, and we had to complete the en-bloc resection with snare. After changing to twothird circumferential incision in the second period of the study, the need for additional snare to complete the en-bloc resection was significantly decreased (from $57.7 \%$ to $13.3 \%$ ).

(6) Postoperative management-it was feasible and safe to resume diet immediately after the procedure and discharge patients the day following ESD without the need for routine blood taking or imaging. In one study from Japan, abdominal computed tomography was performed on day 1 and blood tests were carried out for 2 consecutive days. Oral intake was gradually stepped up and patients were discharged 5 days after ESD. ${ }^{10}$ In contrast, we allowed full diet on the same day after ESD and did not perform computed tomography or blood tests routinely. Our overall median postoperative stay was 1 day. Further 
development of ESD as a day procedure can be explored.

There are a number of limitations in this study. First, this was the learning curve of a single endoscopist and 35 procedures may not be a typical number required for such a learning curve. Second, the inclusion criteria for colorectal ESD were less strict than those in Japan. Lesion less than $2 \mathrm{~cm}$ that could not be removed en bloc would be subjected to ESD instead of piecemeal resection. These kinds of lesion were expected to be easier with shorter operating time. Third, this was a retrospective comparison of two chronological groups which might not have been directly comparable. Lastly, the $7.9 \%$ patient default rate may lead to underestimation of recurrence in this series.

\section{Conclusion}

Untutored colorectal ESD at a low-volume centre was an option in the absence of enough experts to supervise the procedure. Training on an animal model and clinical observation of real-time demonstrations was useful to start ESD without supervision. A cut-off at 35 procedures showed an acceptable $\mathrm{R} 0$ resection rate at a significantly improved procedure time per unit area. There was a second learning curve to achieve a complete ESD procedure without EMR at a higher perforation rate. Colorectal ESD performed by a colorectal surgeon enables any complications to be managed by the same operator, or any lesion unresectable by ESD to be surgically removed. It was not necessary to first perform gastric ESD as the start of ESD training. When more endoscopists have gained experience in colorectal ESD, a structured training programme with accreditation can be established.

\section{Declaration}

All authors have disclosed no conflicts of interest.

\section{References}

1. Tanaka S, Haruma K, Oka S, et al. Clinicopathologica features and endoscopic treatment of superficially spreading colorectal neoplasms larger than $20 \mathrm{~mm}$. Gastrointest Endosc 2001;54:62-6.

2. Walsh RM, Ackroyd FW, Shellito PC. Endoscopic resection of large sessile colorectal polyps. Gastrointest Endosc 1992;38:303-9.

3. Uraoka T, Fujii T, Saito Y, et al. Effectiveness of glycerol as a submucosal injection for EMR. Gastrointest Endosc 2005;61:736-40.

4. Yamamoto H, Kawata H, Sunada K, et al. Successful en-bloc resection of large superficial tumors in the stomach and colon using sodium hyaluronate and small-caliber-tip transparent hood. Endoscopy 2003;35:690-4.

5. Fujishiro M, Yahagi N, Kakushima N, et al. Outcomes of endoscopic submucosal dissection for colorectal epithelial neoplasms in 200 consecutive cases. Clin Gastroenterol Hepatol 2007;5:678-83.
6. Saito Y, Fukuzawa M, Matsuda T, et al. Clinical outcome of endoscopic submucosal dissection versus endoscopic mucosal resection of large colorectal tumors as determined by curative resection. Surg Endosc 2010;24:343-52.

7. The Paris endoscopic classification of superficial neoplastic lesions: esophagus, stomach, and colon: November 30 to December 1, 2002. Gastrointest Endosc 2003;58(6 Suppl):S3-43.

8. Watanabe T, Itabashi M, Shimada Y, et al. Japanese Society for Cancer of the Colon and Rectum (JSCCR) guidelines 2010 for the treatment of colorectal cancer. Int J Clin Oncol 2012;17:1-29.

9. Yoda Y, Ikematsu H, Matsuda T, et al. A large-scale multicenter study of long-term outcomes after endoscopic resection for submucosal invasive colorectal cancer. Endoscopy 2013;45:718-24.

10. Yoshida N, Wakabayashi N, Kanemasa K, et al. Endoscopic submucosal dissection for colorectal tumors: technical difficulties and rate of perforation. Endoscopy 2009;41:758-61.

11. Saito Y, Uraoka T, Yamaguchi Y, et al. A prospective, multicenter study of 1111 colorectal endoscopic submucosal dissections (with video). Gastrointest Endosc 2010;72:1217-25.

12. Taku K, Sano Y, Fu KI, et al. Iatrogenic perforation associated with therapeutic colonoscopy: a multicenter study in Japan. J Gastroenterol Hepatol 2007;22:1409-14.

13. Sano Y, Muto M, Tajiri $H$, et al. Optical/digital chromoendoscopy during colonoscopy using narrow-band image system. Dig Endosc 2005;17(Suppl):S43-8.

14. Ikematsu H, Matsuda T, Emura F, et al. Efficacy of capillary pattern type IIIA/IIIB by magnifying narrow band imaging for estimating depth of invasion of early colorectal neoplasms. BMC Gastroenterol 2010;10:33.

15. Machida H, Sano Y, Hamamoto Y, et al. Narrow-band imaging in the diagnosis of colorectal mucosal lesions: a pilot study. Endoscopy 2004;36:1094-8.

16. Iguchi $M$, Yahagi N, Fujishiro $M$, et al. The healing process of large artificial ulcers in the colorectum after endoscopic mucosal resection [abstract]. Gastrointest Endosc 2003;57:AB226.

17. Asano M. Endoscopic submucosal dissection and surgical treatment for gastrointestinal cancer. World J Gastrointest Endosc 2012;4:438-47.

18. Tanaka S, Tamegai Y, Tsuda S, Saito Y, Yahagi N, Yamano HO. Multicenter questionnaire survey on the current situation of colorectal endoscopic submucosal dissection in Japan. Dig Endosc 2010;22 Suppl 1:S2-8.

19. Probst A, Golger D, Anthuber M, Märkl B, Messmann H. Endoscopic submucosal dissection in large sessile lesions of the rectosigmoid: learning curve in a European center. Endoscopy 2012;44:660-7.

20. Berr F, Wagner A, Kiesslich T, Friesenbichler P, Neureiter D. Untutored learning curve to establish endoscopic submucosal dissection on competence level. Digestion 2014;89:184-93.

21. Białek A, Pertkiewicz J, Karpińska K, Marlicz W, Bielicki D, Starzyńska T. Treatment of large colorectal neoplasms by endoscopic submucosal dissection: a European singlecenter study. Eur J Gastroenterol Hepatol 2014;26:607-15.

22. Teoh AY, Poon CM, Lee JF, et al. Outcomes and predictors of mortality and stoma formation in surgical management of colonoscopic perforations: a multicenter review. Arch Surg 2009;144:9-13.

23. ASGE Technology Committee, Kantsevoy SV, Adler DG, Conway JD, et al. Endoscopic mucosal resection and endoscopic submucosal dissection. Gastrointest Endosc 2008;68:11-8 